\title{
Perancangan Aplikasi Game IQ Test dengan Mengimplementasikan Linear Congruent Method (LCM)
}

\author{
Eky Pambudi Syiamtoni ${ }^{\mathrm{a} 1}$, Iskandar Fitri ${ }^{\mathrm{a} 2}$, Sari Ningsih ${ }^{\mathrm{a} 3}$ \\ anformatika, Fakultas Teknologi Komunikasi dan Informatika, Universitas Nasional \\ Jl. Sawo Manila, Pasar Minggu Jakarta 12520 Indonesia \\ 1ekypambudi@gmail.com \\ 2tektel2001@yahoo.com \\ ${ }^{3}$ sariningsih.lectureseyahoo.com
}

\begin{abstract}
Abstrak
Dengan dilakukannya penelitian mengenai perancangan aplikasi Game IQ Test ini, diharapkan bisa berfungsi sebagai media alternatif yang pada umumnya media pengujiannya masih banyak yang menggunakan kertas, tetapi hal itu kurang efesien karena bisa berdampak buruk pada lingkungan dan mengancam kelestarian hutan, oleh karena itu dengan kemajuan teknologi bisa dimanfaatkan untuk media alternatif dari pemakaian kertas. Perancangan aplikasi Game IQ Test bisa lebih efesien untuk semua pengguna dan lebih ramah untuk lingkungan, karena aplikasi Game IQ Test ini sifatnya mobile dengan menggunakan tools construct 2. Dalam perancangannya dibuat system acak soal, system yang digunakan untuk mengacak soal yaitu dengan memakai Linear Congruent Method atau biasa disebut LCM, LCM adalah membangkit bilangan acak, biasa sering digunakan pada pemprograman computer, sebagian orang yang memakai metode LCM ini pada aplikasinya hanya sebagai pengacak soal agar setiap pengguna mendapatkan bentuk soal yang berbeda. Dari hasil pengujian pada aplikasi Game IQ Test mendapatkan presentase nilai rata - rata 88\% yang menjawab setuju dari penggunaan skala likert.
\end{abstract}

Kata kunci: Construct 2, Game, Linear Congruent Method (LCM), Tes IQ

\section{IQ Test Game Application Design By Implementing Linear Congruent Method}

\begin{abstract}
By carrying out research on the design of the Game IQ Test application, it is hoped that it can function as an alternative media where generally there are still many test media that use paper, but this is less efficient becau se it can have a negative impact on the environment and threaten the sustainability of forests, therefore with technological advances can be used for alternative media from using paper. The design of the Game IQ Test application can be more efficient for all users and more environmentally friendly, because the Game IQ Test application is mobile by using tools construct 2.In its design, use by a random question system is created, the system used to randomize questions is by using the Linear Congruent Method or so-called LCM, LCM is generating random numbers, commonly used in computer programming, some people who use the LCM method in its application are only scramblers of questions so that each user gets a different question form. From the test results on the Game IQ Test application, you get an average value percentage of $88 \%$ who answered agree with the use of the Likert scale.

Keywords: Construct 2, games, Linear Congruent Method (LCM), IQ Test

\section{Pendahuluan}

Perkembangan teknologi software selalu mengiringi perkembangan teknologi dari masa kemasa, yang mendorong pertumbuhan industri kreatif yang terus meningkat. Terbukti dengan banyaknya engine maupun tools yang diciptakan untuk mempermudah pengembang dalam mengembangkan software dari masa kemasa. Salah satu hasil pengembangan software yang saat ini terus di kembangkan adalah teknologi HTML yaitu Construct 2. Construct 2 adalah aplikasi game engine biasa digunakan

dalam membuat aplikasi berbasis HTML5 dan bisa diaplikasikan kebeberapa platform. Maka dari itu peneliti akan membuat aplikasi game $I Q$ Test, $I Q$ Test adalah usaha yang biasa digunakan dalam mengukur tingkat kecerdasan seseorang dengan memberikan sebuah pertanyaan atau suatu masalah dengan waktu tertentu. Dengan menggunakan aplikasi Construct 2, aplikasi yang ingin peneliti buat dapat bisa di digunakan ke dalam platfrorm Android [1]. Oleh karna itu peneliti merancang aplikasi game $I Q$ Test dengan memakai tools Construct 2 bertujuan
\end{abstract}


untuk memudahkan pengguna karna aplikasi ini bisa dikerjakan dengan menggunakan smartphone Android dan juga sebagai media alternative untuk mengurangi penggunaan kertas [2].

Pada Penelitian yang dijelaskan Palupi dan Djuniadi menghasilkan Pengacakan Soal Pada Aplikasi Belajar Hirgana dengan Implementasi Linier Congruent Method [3]. Penelitian yang dilakukan Gunawan dan Dedy menghasilkan Sistem Ujian Online Dengan Pengacakan Soal Menggunakan Linear Congtuent Method [4].

Berdasarkan penelitian yang dilakukan sebelumnya, peneliti menggunakan metode Linier Congruent Method sebagai pengacak soal atau pertanyaan pada aplikasinya, maka dari itu metode Linier Congruent Method adalah metode yang sesuai dengan aplikasi yang akan dirancang [5].

\section{METODE PENELITIAN}

\section{A. Model Waterfall}

Perancangan menggunakan sebuah sistem yaitu model waterfall seperti gambar 1 [6].

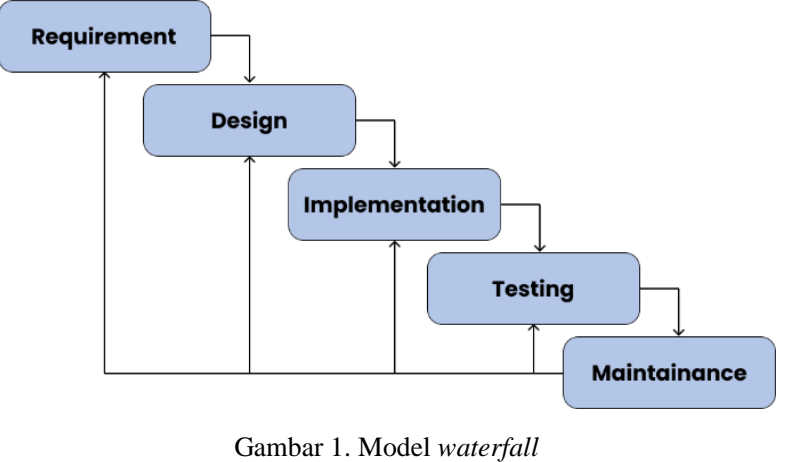

Tahapan pembuatan aplikasi terdiri dari:

1) Kebutuhan (Requirement): Di bagian pertama diperlukan sebuah informasi mengenai kebutuhan software yang diperlukan untuk membuat dan mengetes sebuah aplikasi.

2) Desain (Design): Sesudah itu peneliti harus membuat desain aplikasi yang akan dibuat, ini bertujuan untuk memberikan gambaran lengkap atau tampilan dari aplikasi yang akan dirancang.

3) Implementation (Implementasi): Sesudah tahapan desain, kemudian pada tahapan ini akan menyesuaikan desain dengan program yang akan dibuat.

4) Testing (Pengujian): Sesudah tahapan implementasi, kemudian aplikasi akan dilakukan testing atau pengujian pada aplikasi, dari hasil testing atau pengujian ini yang nantinya dapat melihat apakah terdapat kesalahan atau tidak pada aplikasi yang dirancang.

5) Pemeliharaan (Maintenance): Tahapan terakhir yaitu pemeliharaan, untuk memperbaiki kesalahan pada aplikasi yang terdapat error atau mau penambahkan fitur baru.

\section{B. Linear Congruent Method (LCM)}

Linear Congruent Method adalah metodologi untuk membangunkan sebuah bilangan acak. Ciri dari sifat metode LCM yang terjadi pengulangan dan fungsi LCM (a, c , m) menentukan hasil pengacakan yang berfungsi agar seluruh soal yang telah tersedia akan ditampilkan secara acak, sehingga para pengguna dapat mendapatkan sebuah soal yang berbeda beda setiap mengerjakan soal $I Q$ test tersebut [7]. Maka dari itu perancangan ini dibuat dengan menerapkan konsep LCM dimana pertanyaannya akan diacak dalam waktu tertentu yang berguna untuk meminimalisir kecurangan. Implementasi dari LCM ini menggunakan model dari linear dengan membangunkan sebuah bilangan acak, dijelaskan seperti dibawah ini : [8]

$X_{i}=\left(a\left(X_{i-1}\right)+c\right) \bmod m$

Dimana :

$\mathrm{X}_{\mathrm{i}}=$ Bilangan acak ke- $\mathrm{n}$

$\mathrm{X}_{\mathrm{i}-1}=$ Bilangan acak sebelumnya

a = Pengganda (Multiplier)

$\mathrm{c} \quad=$ Penambahan nilai (Increment)

$\mathrm{m}=(0<\mathrm{m})$ Modulus

Aplikasi game IQ Test dirancangan menggunakan flowchart seperti Gambar 2.

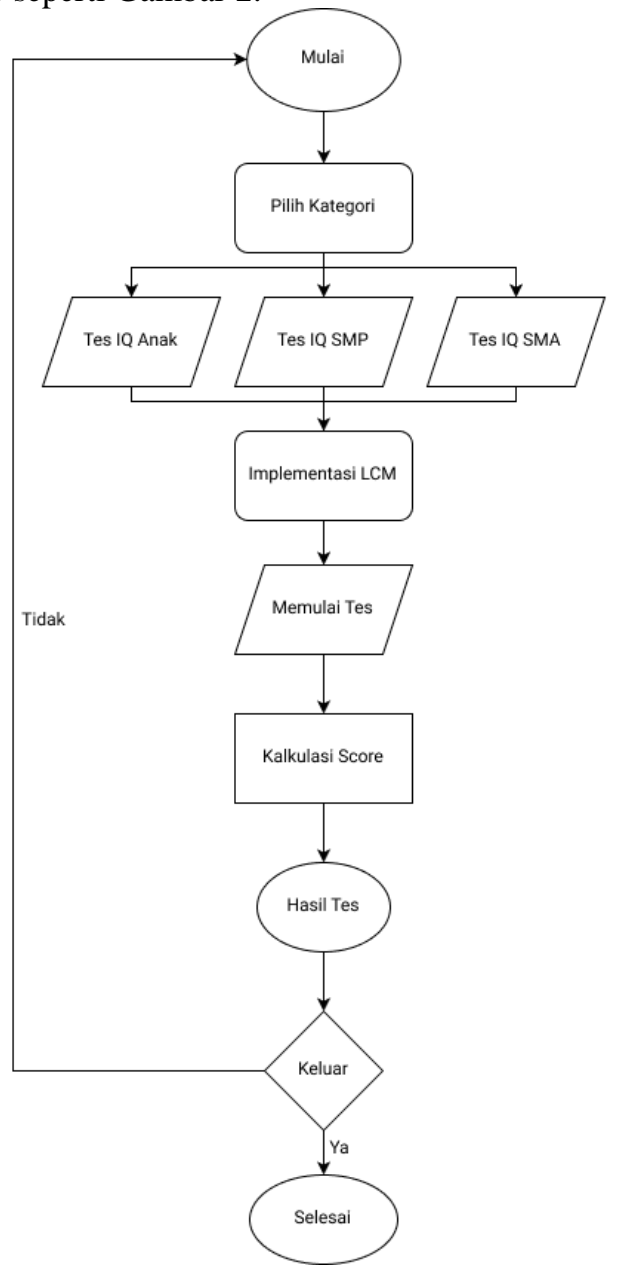

Gambar 2. Flowchart rancangan aplikasi 
Gambar Flowchart menjelaskan alur aplikasi game $I Q$

Test dari :

1. Mulai, ada pada halaman pertama aplikasi

2. Menampilkan pilihan kategori menu $I Q$ Test.

3. LCM diterapkan pada saat ingin memulai $I Q$ Test, dari penerapan LCM, nantinya pengguna akan mendapatkan soal yang mengacak pada waktu periode tertentu.

4. Setelah LCM diimplementasikan maka akan muncul soal untuk memulai test,

5. Setelah itu hasil test akan dihitung dengan otomatis.

6. Sesudah selesai dihitung, nantinya score akan muncul.

7. Pengguna bisa memilih ingin pergi ke halaman awal atau bisa langsung keluar aplikasi.

Implementasi LCM yang diimplementasikan pada aplikasi $I Q$ Test sebagai pengacakan soal. Contoh soal : Peneliti akan membuat percobaan pengacakan soal dalam periode tertentu. Pada contoh soal ini peneliti mempunyai 20 soal (dimulai dari no 0 ).

Jika :

$\mathrm{a}=1$

$\mathrm{c}=7$

$\mathrm{m}=21$

$\mathrm{X}(0)=3$

Penyelesaian :

$\mathrm{X}(0)=4$

$\mathrm{X}(1)=(1(4)+7) \bmod 20=11$

$X(2)=(1(11)+7) \bmod 20=18$

$X(3)=(1(18)+7) \bmod 20=5$

$X(4)=(1(5)+7) \bmod 20=12$

$X(5)=(1(12)+7) \bmod 20=19$

$X(6)=(1(19)+7) \bmod 20=6$

$X(7)=(1(6)+7) \bmod 20=13$

$X(8)=(1(13)+7) \bmod 20=0$

$\mathrm{X}(9)=(1(0)+7) \bmod 20=7$

$X(10)=(1(7)+7) \bmod 20=14$

$X(11)=(1(14)+7) \bmod 20=1$

$X(12)=(1(1)+7) \bmod 20=8$

$X(13)=(1(8)+7) \bmod 20=15$

$X(14)=(1(15)+7) \bmod 20=2$

$X(15)=(1(2)+7) \bmod 20=9$

$X(16)=(1(9)+7) \bmod 20=16$

$X(17)=(1(16)+7) \bmod 20=3$

$X(18)=(1(3)+7) \bmod 20=10$

$\mathrm{X}(19)=(1(10)+7) \bmod 20=17$

Dari penyelesaian di atas diperoleh kemunculan susunan nomor soal yang dibangkitkan dari metode LCM adalah sebagai berikut :

$4,11,18,5,12,19,6,13,0,7,14,1,8,15,2,9,16,3,10$, 17

\section{Metode Penilaian}

Metode penilaian score yang akan diterapkan pada aplikasi game $I Q$ Test ini nantinya tiap-tiap soal yang terjawab dengan benar maka akan mendapatkan nilai sebesar 3 score [9].

Setelah itu ditentukan indeks dari score IQ Test seperti Tabel 1.

TABEL I

SCORE IQ DAN INDEKS

\begin{tabular}{|l|l|}
\hline Hasil Score IQ & Indeks \\
\hline$<70$ & Terbelakang \\
\hline $70-89$ & Kecerdasan Rendah \\
\hline $90-110$ & Kecerdasan Sedang \\
\hline $111-120$ & Kecerdasan Tinggi \\
\hline $121-130$ & Cerdas \\
\hline$>130$ & Genius \\
\hline
\end{tabular}

Pada Tabel 1 menjelaskan suatu indeks dan penilaian aplikasi game IQ Test, diawali dari score yang terkecil terlebih dahulu yaitu 70 yang berarti pengguna memiliki keterbelakangan, kemudian sampai dengan score diatas 130 yang berarti pengguna memiliki indeks genius [10]

\section{HASIL DAN PEMBAHASAN}

\section{A. Analisa Kebutuhan Sistem}

Implementasi peracangan aplikasi ini diperlukan sebuah analisa sistem yang diapakai untuk menjalankan proses perancangan aplikasi, ada analisis kebutuhan perangkat lunak dan juga analisisa kebutuhan perangkat keras : [11]

1. Analisa Kebutuhan Perangkat Keras:

Laptop, Processor Intel® CoreTM i5-3320M CPU @

2.60GHz 2.60GHz 64-bit dengan RAM 8 GB.

2. Analisa Kebutuhan Perangkat Lunak:

a. Draw.io, dipakai sebagai pembuatan flowchart.

b. Figma, dipakai sebagai perancang tampilan aplikasi $I Q$ Test.

c. PhoneGap, dipakai sebagai pengubah hasil export HTML 5 Construct 2 menjadi APK.

d. Construct 2, dipakai sebagai perancangan Game.

\section{B. Penggunaan Tools}

Pada Gambar 3, memperlihatkan halaman pembuatan layout yang berfungsi sebagai penataan sebuah layout dan juga assets dalam pembuatan aplikasi. 


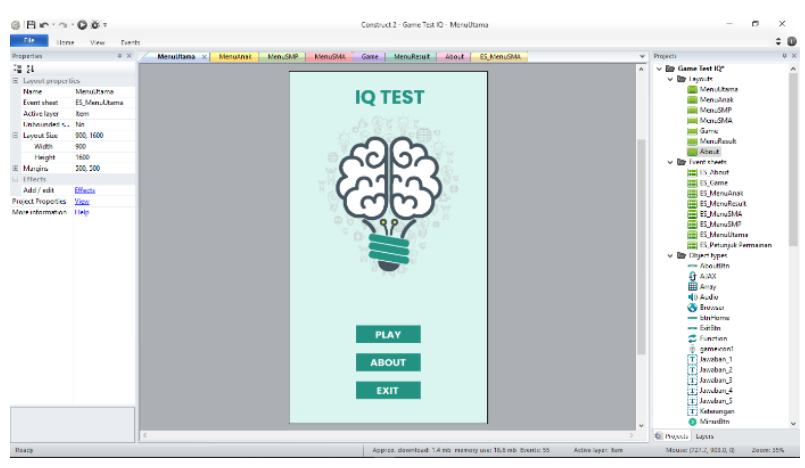

Gambar 3. Mengatur layout pada construct 2

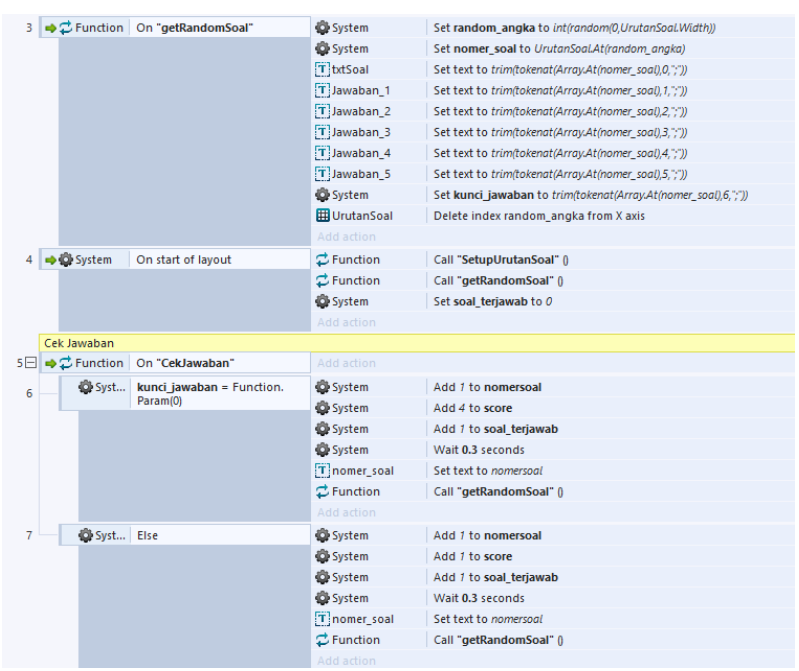

Gambar 4. Mengatur sistem aplikasi

Gambar 4 memperlihatkan halaman mengatur sistem aplikasi yang berfungsi sebagai pembuatan alur pada aplikasi $I Q$ Test yang akan dibuat agar soal dari $I Q$ Test menjadi random atau mengacak.

\section{Tampilan Aplikasi}

Tampilan aplikasi dari hasil perancangan aplikasi game $I Q$ Test yang telah dibuat dengan menggunakan Figma terlihat seperti pada berikut : [12]

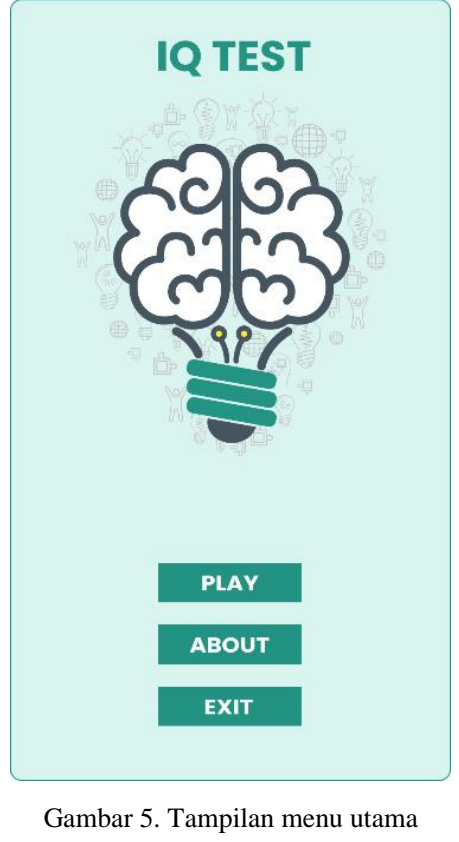

Gambar 5 adalah halaman menu utama ketika aplikasi game $I Q$ Test pertama kali dijalankan. Di menu utama ini hanya menampilkan button play untuk memulai $I Q$ Test, button about untuk menampilkan informasi tentang $I Q$ Test dan button exit untuk menutup aplikasi.

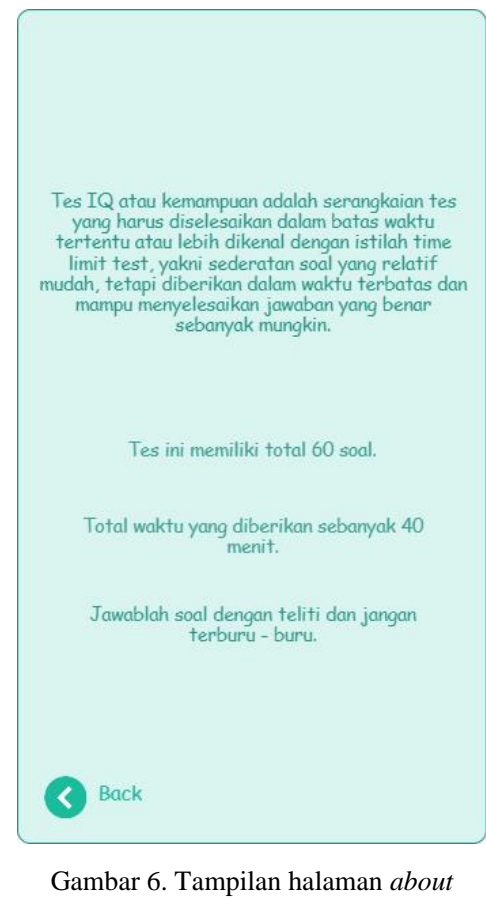

Pada gambar 6 adalah tampilan halaman about yang berfungsi memberikan keterangan terkait aplikasi game $I Q$ Test. 


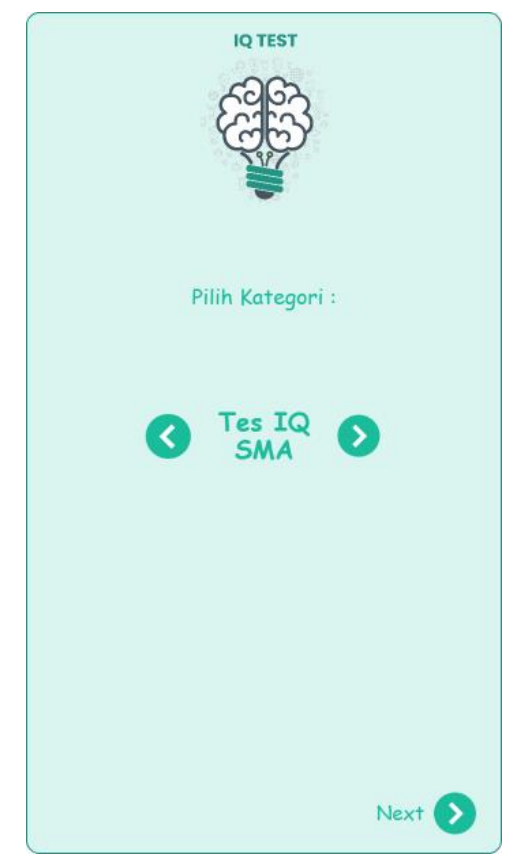

Gambar 7. Tampilan halaman pilih kategori

Pada Gambar 7 adalah tampilan halaman pilih kategori, halaman ini akan muncul setelah mengklik button play, halaman ini berfungsi agar para pengguna dapat memilih kategori $I Q$ Test, sesuai dengan apa yang mereka inginkan.

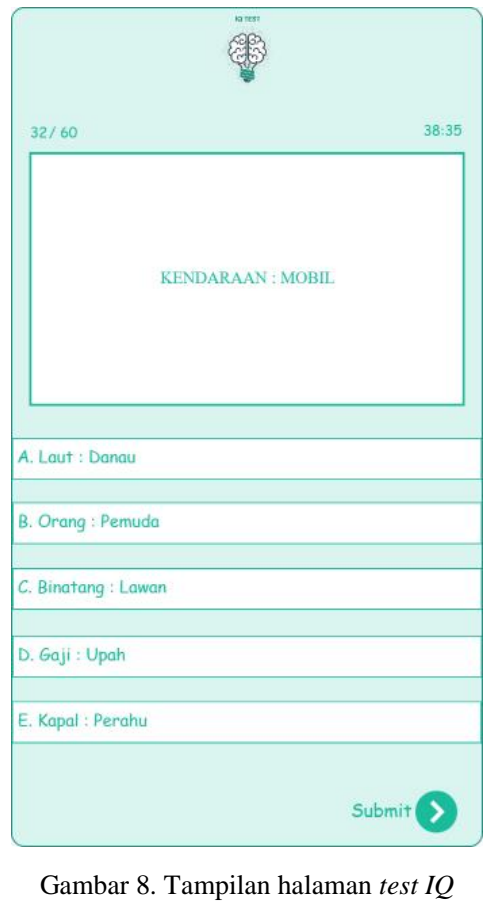

Pada gambar 8 adalah tampilan soal - soal $I Q$ test yang dimana user harus menjawab soal yang ada dengan waktu tertentu.

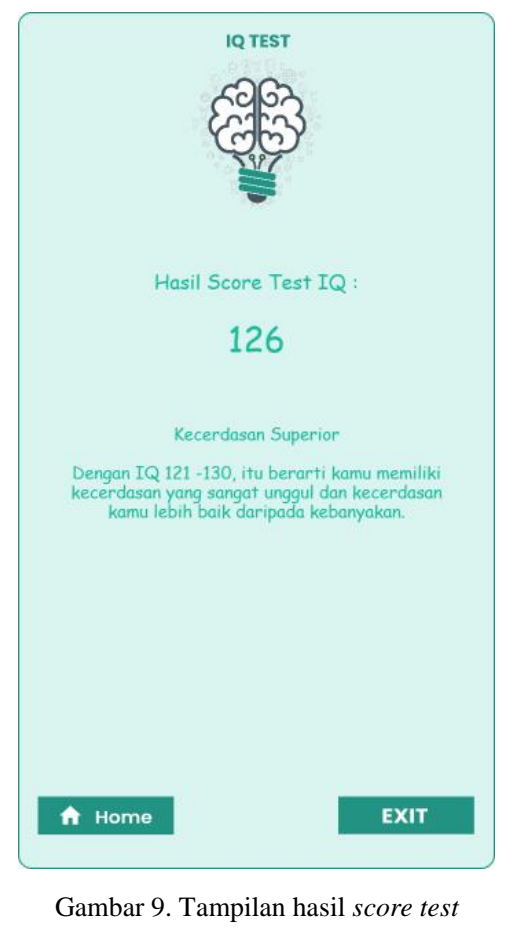

Pada gambar 9 adalah tampilan hasil score IQ Test dan terdapat indeks dari hasil soal yang sudah user kerjakan sebelumnya.

\section{Pengujian Pada Device}

Tahap Pengujian dilakukan menggunakan device Android, Dilakukannya pengujian ini bermaksud agar bisa diketahui apakah aplikasi ini dapat digunakan atau belum oleh user. Indeks dari keberhasilan pada pengujian ini bersumber pada versi device Android. Pengujian dibuat pada 5 versi Android.

Dibawah ini adalah tabel pengujian yang dilakukan pada beberapa versi Android, Tabel 2 :

TABEL III

PENGUJIAN PADA SMARTPHONE ANDROID

\begin{tabular}{|l|l|}
\hline Jenis Device Android & Hasil \\
\hline $\begin{array}{l}\text { Android 1 } \\
\text { OS Android 6.0 }\end{array}$ & Berhasil dimainkan \\
\hline $\begin{array}{l}\text { Android 2 } \\
\text { OS Android 7.0 }\end{array}$ & Berhasil dimainkan \\
\hline $\begin{array}{l}\text { Android 3 } \\
\text { OS Android } 8.0\end{array}$ & Berhasil dimainkan \\
\hline $\begin{array}{l}\text { Android 4 } \\
\text { OS Android } 9.0\end{array}$ & Berhasil dimainkan \\
\hline $\begin{array}{l}\text { Android 5 } \\
\text { OS Android 10 }\end{array}$ & Berhasil dimainkan \\
\hline
\end{tabular}

\section{E. Pengujian Game}

Tahap pengujian ini dengan menggunakan kuesioner yang didapat dari 50 pengguna, dengan pengujian menggunakan skala likert yang ditampilkan pada tabel 3 . 
Dibawah ini adalah tabel pertanyaan pada kuesioner yang harus di jawab pengguna.

TABEL IIIII

PERTANYAAN KUESIONER

\begin{tabular}{|l|l|}
\hline No & Pertanyaan \\
\hline 1 & $\begin{array}{l}\text { Apakah menu dalam aplikasi sudah sesuai dengan } \\
\text { fungsinya? }\end{array}$ \\
\hline 2 & Apakah tombol pada permainan mudah digunakan? \\
\hline 3 & Apakah warna pada aplikasi menarik untuk anda? \\
\hline 4 & $\begin{array}{l}\text { Apakah waktu yang digunakan dalam IQ Test sudah } \\
\text { sesuai ? }\end{array}$ \\
\hline 5 & Apakah aplikasi ini menyenangkan untuk belajar? \\
\hline
\end{tabular}

Setelah itu hasil dari kuesioner dihitung dengan memakai skala likert. Dengan rumus :

$S L=$ Jumlah responden $x$ Bobot jawaban

Dibawah ini adalah tampilan dari hasil kuesioner yang telah diisi oleh pengguna.

\section{Hasil Kuesioner}

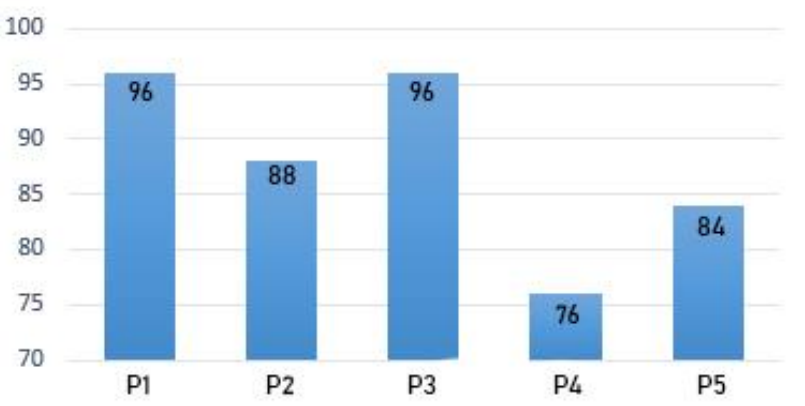

Gambar 10. Hasil kuesioner

Gambar 10 merupakan hasil dari kuesioner yang memilih setuju disetiap pertanyaan yang dijawab oleh pengguna.

P1 atau pertanyaan 1 memperoleh nilai 96 ,

$\mathrm{P} 2$ atau pertanyaan 2 memperoleh nilai 88 ,

P3 atau pertanyaan 3 memperoleh nilai 98,

P4 atau pertanyaan 4 memperoleh nilai 76 ,

P5 atau pertanyaan 5 memperoleh nilai 84 ,

Didapatnya hasil persentase nilai rata-rata sebesar $88 \%$ yang menjawab setuju.

\section{KESIMPULAN}

Berdasarkan dari hasil pembahasan dan penjelasan yang didapat peneliti, dapat disimpulkan bahwa :

1. Aplikasi Game IQ Test ini mengimplementasikan Linear Congruent Method sebagai penyusun sebuah soal atau pertanyaan dimana pengacakan kemunculan soal akan terjadi pengulangan pada waktu tertentu.

2. Aplikasi Game IQ Test bisa digunakan dengan mudah karna bisa dikerjakan pada smartphone Android dan Web Browser dan juga sebagai media alternative untuk mengurangi penggunaan kertas.

3. Pada Apliakasi Game IQ Test tidak harus menunggu lama untuk melihat hasil IQ Test karna akan langsung muncul pada saat selesai mengerjakan tes yang pada umumnya hasil IQ Test harus menunggu beberapa hari untuk mengetahui hasilnya.

\section{DAFTAR PUSTAKA}

[1] A. D. Hartanto, W. Mega, P. Dhuhita, and A. Tinangon, "PERANCANGAN GAME MULTIPLATFORM MENGGUNAKAN SCIRRA CONSTRUCT 2 DAN HTML 5 E-91 E-92," pp. 91-98, 2014.

[2] V. Maarif, A. E. Widodo, and D. Y. Wibowo, "Aplikasi Tes IQ Berbasis Android," ijse.bsi.ac.id IJSE - Indones. J. Softw. Eng. ISSN, vol. 3, no. 2, pp. 2461-690, 2017.

[3] D. P. T. Wardani, "Implementasi Linier Congruent Method Untuk Pengacakan Soal Ujian Pada Aplikasi Belajar Hiragana," Edu Komputika J., vol. 2, no. 2, pp. 29-39, 2015, doi: 10.15294/edukomputika.v2i2.7856.

[4] G. Gunawan and D. A. Prabowo, "SISTEM UJIAN ONLINE SELEKSI PENERIMAAN MAHASISWA BARU DENGAN PENGACAKAN SOAL MENGGUNAKAN LINEAR CONGRUENT METHOD (Studi Kasus di Universitas Muhammadiyah Bengkulu)," J. Inform. Upgris, vol. 3, no. 2, pp. 143-151, 2017, doi: 10.26877/jiu.v3i2.1872.

[5] D. S. Utama and Y. Asriningtias, "Perbandingan Waktu Akses Algoritma Fisher-Yates Shuffel Dan Linear Congruent Method Pada Soal Try-Out Berbasis Web," JISKA (Jurnal Inform. Sunan Kalijaga), vol. 2, no. 2, p. 93, 2017, doi: 10.14421/jiska.2017.22-04.

[6] R. Tullah, M. Iqbal, and A. S. Cahyadiputra, "Perancangan Aplikasi Simulasi Tes IQ Untuk Tingkat SLTA Berbasis Web," J. SISFOTEK Glob., vol. 5, no. 1, pp. 31-36, 2018.

[7] D. Irsa, W. Wiryasaputra, and S. Primaini, "Perancangan Aplikasi Game Edukasi Pembelajaran Anak Usia Dini Menggunakan Linear Congruent Method ( Lcm ) Berbasis Android," J. Inform. Glob., vol. 6, no. 1, pp. 7-14, 2015.

[8] A. Marwan, Sutardi, and R. Ramadha, "Penerapan Metode Linear Congruent Method (Lcm) dalam Perancangan dan Pembuatan Game Monopoli Edukasi untuk Tokoh Pahlawan Nasional," SemanTIK, vol. 3, no. 1, pp. 229-236, 2017.

[9] M. M. Raditya, F. Fauziah, and R. T. Komalasari, "Rancang Bangun Game IQ Test Preparation dengan Mengimplementasikan Metode FSM," J. Sist. dan Teknol. Inf., vol. 8, no. 1, p. 128, 2020, doi: 10.26418/justin.v8i1.37941.

[10] I. A. Saputra, J. A. Widians, and Rosmasari, "Aplikasi Sistem Pakar Skoring Tes Iq Dengan Alat Cfit Berbasis Desktop," Univ. Mulawarman, vol. 2, no. 1, pp. 146-151, 2017.

[11] T. L. T. J. C. Sitanggang, "Aplikasi Pengacak Soal Ujian Berkategori Menggunakan Metode LCM (Linear Congruent Method)," MEANS (Media Inf. Anal. dan Sist., 2016.

[12] J. A. Yustin, H. Sujaini, and M. A. Irwansyah, "Rancang bangun aplikasi game edukasi pembelajaran matematika menggunakan construct 2," J. Sist. dan Teknol. Inf., vol. 1, no. 1, pp. 1-5, 2016. 